\title{
Technical note: Near infrared reflectance spectroscopy to predict fecal indigestible neutral detergent fiber for dairy cows
}

\author{
N. Brogna, ${ }^{* 1}$ A. Palmonari, ${ }^{*}$ G. Canestrari, ${ }^{*}$ L. Mammi, ${ }^{*}$ A. Dal Prà, $\dagger$ and A. Formigoni ${ }^{*}$ \\ *Department of Veterinary Medicine, Università di Bologna, 40064, Bologna, Italy \\ †Centro Ricerche Produzioni Animali (C.R.P.A.) S.p.A., 42121 Reggio Emilia, Italy
}

\begin{abstract}
In vitro and in situ procedures performed to estimate indigestible neutral detergent fiber (iNDF) in forage or fecal samples are time consuming, costly, and limited by intrinsic factors. In contrast, near infrared reflectance spectroscopy (NIRS) has become widely recognized as a valuable tool for accurately determining chemical composition and digestibility parameters of forages. The aim of this study was to build NIRS calibrations and equations for fecal iNDF. In total, 1,281 fecal samples were collected to build a calibration data set, but only 301 were used to develop equations. Once dried, samples were ground and chemically analyzed for crude protein, ash, amylase and sodium sulfite-treated NDF corrected for ash residue (aNDFom), acid detergent fiber, acid detergent lignin, and in vitro digestion at 240 $\mathrm{h}$ to estimate iNDF (uNDF240). Each fecal sample was scanned using a NIRSystem 6500 instrument (Perstorp Analytical Inc., Silver Spring, MD). Spectra selection was performed, resulting in 301 sample spectra used to develop regression equations with good accuracy and low standard error of prediction. The standard error of calibration (SEC), cross validation (SECV), and coefficients of determination for calibration $\left(\mathrm{R}^{2}\right)$ and for cross validation $(1-\mathrm{VR}$, where $\mathrm{VR}=$ variance ratio $)$ were used to evaluate calibration and validation results. Moreover, the ratio performance deviation (RPD) and ratio of the range of the original data to SECV (range/ SECV; range error ratio, RER) were also used to evaluate calibration and equation performance. Calibration data obtained on fiber fractions aNDFom $\left(\mathrm{R}^{2}=0.92\right.$, $1-\mathrm{VR}=0.87, \mathrm{SEC}=1.48, \mathrm{SECV}=1.89, \mathrm{RPD}=$ 2.80 , and $\mathrm{RER}=20.19)$, $\mathrm{uNDF} 240\left(\mathrm{R}^{2}=0.92,1-\mathrm{VR}\right.$ $=0.86, \mathrm{SEC}=1.65, \mathrm{SECV}=2.24, \mathrm{RPD}=2.57$, and RER $=14.30)$, and in vitro rumen aNDFom digestibility at $240 \mathrm{~h}\left(\mathrm{R}^{2}=0.90,1-\mathrm{VR}=0.85, \mathrm{SEC}=2.68\right.$,
\end{abstract}

Received June 12, 2017.

Accepted October 10, 2017.

${ }^{1}$ Corresponding author: info@nicobrogna.it
$\mathrm{SECV}=3.43, \mathrm{RPD}=2.53$, and $\mathrm{RER}=14.0)$ indicated the predictive equations had good predictive value.

Key words: undigested NDF, fecal composition, near infrared reflectance spectroscopy

\section{Technical Note}

Ruminal digestion of NDF is linked to the part of NDF that is indigestible and the rate at which the potentially digestible NDF is fermented. Indigestible NDF (iNDF; determined by in situ or in vitro procedures) is reported to be a reliable digestibility marker in controlled animal experiments (Lippke et al., 1986; Huhtanen et al., 1994, 2006a; Lund et al., 2007). The standard nomenclature throughout the literature refers to "indigestible NDF" (Mertens, 1993; Huhtanen et al., 2006b). To improve the accuracy of the standard terminology used to describe fiber fermentation dynamics, Mertens (2013) coined the term "undigested NDF" (uNDF) as the laboratory measure of indigestible NDF at a specified fermentation time. The uNDF fraction could be estimated via long-term $(240 \mathrm{~h})$ in vitro fermentations (uNDF240; Palmonari et al., 2016) or by incubating the samples in bags placed in the rumen for $288 \mathrm{~h}$. However, this procedure relies on the availability of cannulated cows and is limited by the intrinsic characteristics of the bags used (Huhtanen et al., 2006a; Krizsan et al., 2012). The uNDF240 fraction represents the fiber fraction that affects physical effectiveness, digestion, passage rates, and gut fill of forages (Van Amburgh et al., 2015). Moreover, by measuring fecal iNDF output, we could acquire additional information on the proportion of potentially digestible NDF really digested in vivo. Furthermore, fecal uNDF is useful as an intrinsic digestibility marker compared with total fecal collection (Lee and Hristov, 2013) for a total-tract nutrient digestibility estimation for dairy cows (Ferraretto et al., 2015).

According to Palmonari et al. (2016), uNDF240 should be included in routine forage and feed analysis because it offers a more predictable digestibility and uniformity than NDF alone. As reported above, wet 
chemical analyses have been used to characterize forages and predict their nutritive value. However, these are time consuming (especially regarding uNDF240 determination) and costly, and may involve the use of hazardous chemicals. Near infrared reflectance spectroscopy (NIRS) has become widely recognized as a valuable tool in accurate determination of the chemical composition of a wide range of forages (Shenk and Westerhaus, 1985; Redshaw et al., 1986) and in the prediction of digestibility parameters (Norris et al., 1976; Barber et al., 1990; Park et al., 1997). A close relationship between NIRS and iNDF of grass silage was reported first by Nousiainen et al. (2004), and robust NIRS calibrations are already available, using C3 and C4 forages, for the prediction of iNDF (Harper et al., 2014). Although several studies have been conducted, no experiments have shown the correlation between NIRS spectra and fecal uNDF of dairy cows, especially using long in vitro incubations in individual batch fermentation systems. The aim of this work was to construct NIRS calibrations and equations for fecal uNDF240, using an in vitro approach, to aid nutritionists to adapt the cow response to forage quality, improving the efficiency of use of forage fiber in diet for dairy cows.

In total, 1,281 fecal samples were collected but only 301 were used to build the calibration. The samples were collected by rectal grab from cows involved in 4 feeding trials. In the first trial (157 original samples, 39 selected for calibration), heifers were fed with dried, ground, and pelleted grass hay of different quality mixed with TMR (Bonfante et al., 2016). In the second trial (548 original samples, 113 selected for calibration), lactating cows were fed a diet based on alfalfa that differed in harvest times and digestibility (Fustini et al., 2017). In the third trial (257 original samples, 25 selected for calibration), lactating cows were fed a diet based on grass hay with various levels of soybean and rapeseed meal as the main protein source. In the fourth trial (127 original samples, 51 selected for calibration), lactating cows were fed a diet of grass and alfalfa hay with different starch sources (flaked corn or sorghum meal). Moreover, to achieve as much variability as possible, an additional sampling campaign was planned directly on commercial farms. Eight farms were selected for this purpose. In 4 of them, animals were fed a corn silage-based diet, and in the remaining 4, the diet was based on grass and alfalfa hay. For each farm, one sample each was collected from 5 early-lactation cows, 5 mid-lactation cows, 5 late-lactation cows, and 5 dry cows. Another 4 samples were obtained as a pool of 5 cows in each category, for a total of 24 samples per farm and an overall total of 192 samples (73 selected for calibration). Once collected, each sample was immediately dried in a forced-air oven at $65^{\circ} \mathrm{C}$ for $48 \mathrm{~h}$ to determine DM content and was ground through a 1-mm screen in a Foss Tecator Cyclotec Sample Mill (model 1093; Foss Tecator, Höganäs, Sweden) for chemical and digestibility analysis. The samples were analyzed for amylase-treated ash-corrected NDF with addition of sodium sulfite (aNDFom) as suggested by Mertens (2002), refluxing $0.5 \mathrm{~g}$ of sample for $1 \mathrm{~h}$ at boiling temperature in a medium-porosity crucible, using a Fibertec 2010 system (Foss Tecator). The samples were also analyzed for ADF and ADL (AOAC, 1990; method 973.18), CP (AOAC, 1990; methods 976.06 and 984.13, copper catalyst Kjeldahl method) using a Kjeldahl nitrogen/protein analyzer (Gerhadt Vapodest 50, Gerhardt GmbH, Königswinter, Germany), ash, which was determined after 4 -h combustion at $550^{\circ} \mathrm{C}$ in a muffle furnace, and starch (AOAC, 1990). As a good predictor of uNDF, in vitro rumen aNDFom digestibility at $240 \mathrm{~h}$ (IVNDFD240) was determined using the Tilley and Terry modified technique (Tilley and Terry, 1963; Robertson and Van Soest, 1981), according to the procedure described by Palmonari et al. (2017). Briefly, basic procedures consisted of incubating $0.5 \mathrm{~g}$ of dried and ground fecal sample in a $150-\mathrm{mL}$ Erlenmeyer flask under $\mathrm{CO}_{2}$ back-pressure at $39^{\circ} \mathrm{C}$ in a water bath for $240 \mathrm{~h}$; the flask contained rumen fluid, buffer medium, and macro- and micromineral solution (Goering and Van Soest, 1970). Each sample was analyzed in triplicate. Rumen fluid was collected from 2 lactating cows fed a hay-based diet (milk production $=33.2 \pm 1.7$ $\mathrm{kg} / \mathrm{d} ; 251 \pm 2 \mathrm{DIM}$ ) containing grass hay and alfalfa, corn barley and sorghum as energy source, and soybean meal as protein source (Palmonari et al., 2016). Rumen fluid was mixed and placed in a $\mathrm{CO}_{2}$-gassed insulated bottle. Rumen contents were filtered through 4 layers of cheesecloth and kept under constant $\mathrm{O}_{2}$-free $\mathrm{CO}_{2}$ flow before inoculating each flask. After $240 \mathrm{~h}$ of incubation, sample residues were analyzed to determine the aNDFom content, following the procedure described by Mertens (2002), which represents the uNDF240 of the fecal samples determined in these conditions. The duration of incubation was based on previous experiences that showed $240 \mathrm{~h}$ to be the maximum length for in vitro fiber digestion under anaerobic conditions (Fox et al., 2004; Raffrenato and Van Amburgh, 2010; Cotanch et al., 2014). Indigestible aNDFom, after a 240-h incubation, is determined after an incineration step at $550^{\circ} \mathrm{C}$ for $3 \mathrm{~h}$ and is expressed on an $\mathrm{OM}$ basis as a percentage of DM. The IVNDFD240 (percentage of aNDFom) was also determined for each fecal sample, from the same assay, using standard calculations (Goering and Van Soest, 1970).

For spectra acquisition, each fecal sample was packed into cylindrical sample holders equipped with a quartz window and scanned (wavelength between 400 and 
$2.498 \mathrm{~nm}$ ) using a NIRS instrument fitted with a spinning cup holder (NIRSystem 6500; Perstorp Analytical Inc., Silver Spring, MD). Near infrared spectra (log 1 /reflectance) were recorded for each 2-nm interval. Population characterization based on spectral variability of the samples was evaluated using the CENTER algorithm (Shenk and Westerhaus, 1991a,b) included in the WinISI II software package (version 1.5; Infrasoft International, Port Matilda, PA), with a maximum standardized Mahalanobis distance $(\mathrm{H})$ from the average spectrum of 3.0. Low average neighbor spectra $(\mathrm{NH})$ distance characterized the spectral database, leading to poor results in attempting a first calibration and equation using the whole data set of 1,281 original samples (data not shown). To avoid redundant samples and any over-fitting, which could cause misleading calibration and poor performance of prediction, spectra selection was performed by using the SELECT function of WinISI II software, a PCA analysis based on NH distance of the spectra population (Shenk and Westerhaus, 1991a,b). This procedure, with neighbor H set to 0.6 , resulted in 301 sample spectra selected for the calibration data set as described above.

Mathematical treatments of spectral data were performed with WinISI II (version 1.5), exploring different math transformations for scatter correction and numbers of modified partial least squares (MPLS) terms in the models. The standard normal variate and detrending (SNV-D) method was applied for scatter correction (Barnes et al., 1989), together with first- or secondorder derivative as mathematical treatment, to avoid noise not belonging to the sample that could bring misleading information to the spectra. The best predictive model was achieved using first-order derivative, with gaps and smoothing each 4 data points. The MPLS regression technique was used to develop chemometric models, using the full near infrared wavelength range $(1,100-2,500 \mathrm{~nm})$ and selecting a wavelength each $8 \mathrm{~nm}$ for a total of 173 wavelengths. An optimum number of MPLS terms was determined by maximizing coefficients of determination $\left(\mathrm{R}^{2}\right)$ and minimizing standard errors of calibration (SEC; Shenk and Westerhaus, 1991a). Calibration performance was evaluated using the crossvalidation technique (Shenk and Westerhaus, 1991b). The statistics used for the evaluation of the model were SEC and standard error of cross-validation (SECV) and coefficient of determination for the calibration $\left(\mathrm{R}^{2}\right)$ and for the cross-validation $(\mathbf{1}-\mathbf{V R}$, where VR = variance ratio). The ratio of performance deviation (RPD), calculated as the ratio of the standard deviation of the original data to the SECV (Williams, 2004) and the range error ratio (RER), the ratio of the range of the original data to SECV, were also used to evaluate the calibration performance.

Fecal composition and in vitro fiber digestibility data are reported in Table 1. In the calibration data set $(\mathrm{n}=$ 301), not all samples were analyzed for each parameter. However, for fiber composition and IVDNDF240 data, almost all samples were available. The fecal samples used for calibration varied in their chemical composition and digestibility. In particular, $\mathrm{CP}$ and ash ranged from 7.90 to 22.15 , and from 7.77 to $19.91 \%$ of DM, respectively. Starch, despite fewer analyses, ranged from 0.18 to $6.04 \%$ of DM, and especially the fiber fraction and IVDNDFD240 showed a range of variability, demonstrating a good result of the selection process. Comparing the average composition of fecal samples, in agreement with other works (Fredin et al., 2014; Bonfante et al., 2016), with that of a general diet for dairy cows (Mentink et al., 2006; Bonfante et al., 2016), the disappearance of the $\mathrm{OM}$ digestible fraction and the concentration of the indigestible and inorganic fraction

Table 1. Summary statistics of fecal composition and 240-h in vitro digestibility for the samples used in the calibration data set

\begin{tabular}{lrrrrrr}
\hline Constituent $^{1}$ (\% of DM) & \multicolumn{1}{c}{$\mathrm{n}^{2}$} & Minimum & Maximum & Range $^{3}$ & Mean & SD \\
\hline DM & 228 & 10.02 & 21.99 & 11.97 & 14.90 & 2.02 \\
CP & 103 & 7.90 & 22.15 & 14.25 & 13.58 & 3.13 \\
Starch & 71 & 0.18 & 6.04 & 5.86 & 1.72 & 1.11 \\
Ash & 126 & 7.77 & 19.91 & 12.14 & 11.98 & 2.59 \\
ADF & 301 & 28.70 & 85.36 & 56.66 & 43.95 & 6.64 \\
ADL & 276 & 9.42 & 43.05 & 33.63 & 16.63 & 6.32 \\
aNDFom & 301 & 43.85 & 81.97 & 38.12 & 59.98 & 5.62 \\
uNDF240 & 300 & 27.36 & 59.35 & 31.99 & 43.88 & 6.27 \\
IVNDFD240 (\% aNDFom) & 300 & 4.40 & 52.46 & 48.06 & 26.67 & 9.40 \\
\hline
\end{tabular}

${ }^{1}$ aNDFom $=$ amylase and sodium sulfite-treated NDF, corrected for ash residue; $\mathrm{uNDF} 240=$ undigested NDF estimated via 240 -h in vitro fermentation; IVNDFD240 = in vitro aNDFom digestibility after $240 \mathrm{~h}$ of incubation.

${ }^{2} \mathrm{n}=$ number of sample analyses.

${ }^{3}$ Range $=$ maximum - minimum. 
of the diet were immediately evident, except for $\mathrm{CP}$, where the fecal concentration is affected by microbial protein and flaking cells excretion.

The number of MPLS terms, the number of samples used for NIRS equations, the calibration, and cross-validation statistics are reported in Table 2. The number of samples used in the calibration equations may be less than the total number of samples available, because outliers identified by the 2-tailed Student's $t$-test, were not used to develop the calibration equations. The fraction of variance accounted for each MPLS calibration was relatively high for almost all components $\left(\mathrm{R}^{2}>\right.$ $0.90)$, except for $\mathrm{DM}\left(\mathrm{R}^{2}=0.77\right)$ and starch $\left(\mathrm{R}^{2}=\right.$ 0.66). After cross-validation, the coefficient of determination $(1-\mathrm{VR})$ for almost all components was, on average, 0.06 points lower than the $\mathrm{R}^{2}$ of the calibration, with the exception of DM and starch. For DM, the low correlation could be related to the fact that samples were dried before scanning, whereas for starch, the wide difference between $R^{2}$ and 1 - VR suggested that more samples are required to strengthen the calibration. However, the calibration for starch looked promising and as reported in previous work (Fredin et al., 2014), robust calibrations for fecal starch are already available, and many feed laboratories in the United States offer such NIRS analysis to professional customers.

In regards to fecal uNDF240, and considering the peaks' correlation with SNV-D (standard normal variate and detrending) spectra, clear absorption was observed in the region 1,900 to $2,000 \mathrm{~nm}$, at $2,450 \mathrm{~nm}$, and in the regions 1,150 to $1,650 \mathrm{~nm}$ and 2,000 to 2,350 $\mathrm{nm}$, as reported by Nousiainen et al. (2004). Compared with grass silage, the difference in the shape and amplitude of the peaks obtained in the present work can be related to higher levels of NDF and uNDF240 found in fecal samples. Even if comparable NIRS data for fecal samples (and especially for uNDF240 and IVNDFD240) are not available in the literature, the good correlation among peaks between spectra suggests that a good prediction equation could be developed. Williams and Sobering (1996) considered that RPD value should be at least 3 and RER at least 10 . Looking at these accuracy indicators in Table 2, the RER values were, in all cases, $>10$ and, in some cases, $>20$ (aNDFom, ADF), and the RPD values were $>2.5$ for almost all components except DM (1.69), starch (1.35), and ADL (2.42), suggesting a proper calibration. Despite the limited number of samples, the relatively high $\mathrm{R}^{2}$ and $1-\mathrm{VR}$ values for $\mathrm{CP}$ and ash could be related to the fact that $\mathrm{CP}$ is a nitrogen compound, chemically well defined, whereas ash represents the inorganic portion of the sample and is well predicted by NIRS as the difference between DM and OM. Compared with values for $C P$, the $R^{2}$ and $1-V R$ values were lower for uNDF240 and IVNDFD240. As reported by Berzaghi et al. (1997) and shown by Nousiainen et al. (2004), these results were expected, because fiber fractions, in general, are not composed of a single defined compound but combine different chemical entities involving several regions of spectral absorptions, altering the real relationship between the spectra and reference method. In addition, the laboratory procedures for uNDF240, IVNDFD240, and aNDFom could have larger analytical error compared with that for $\mathrm{CP}$ and ash due to the complexity of such methods. Other authors have also noted that the main source of inaccuracy in the calibration process is sampling and internal laboratory error, in relationship to the range of the given nutrient

Table 2. Calibration and cross-validation statistics for near infrared spectroscopy analysis of fecal chemical composition and 240-h in vitro digestibility

\begin{tabular}{|c|c|c|c|c|c|c|c|c|c|c|}
\hline \multirow[b]{2}{*}{ Constituent $^{1}$ ( $\%$ of DM) } & \multirow[b]{2}{*}{$\mathrm{n}$} & \multicolumn{5}{|c|}{ Calibration statistics $^{2}$} & \multicolumn{4}{|c|}{ Cross validation statistics ${ }^{3}$} \\
\hline & & MPLS terms & Mean & $\mathrm{SD}$ & SEC & $\mathrm{R}^{2}$ & SECV & $1-\mathrm{VR}$ & $\mathrm{RPD}$ & RER \\
\hline $\mathrm{CP}$ & 92 & 9 & 13.30 & 2.90 & 0.74 & 0.93 & 1.08 & 0.86 & 2.68 & 13.20 \\
\hline Starch & 65 & 6 & 1.48 & 0.74 & 0.43 & 0.66 & 0.55 & 0.51 & 1.35 & 10.74 \\
\hline Ash & 116 & 9 & 11.81 & 2.49 & 0.75 & 0.91 & 0.98 & 0.84 & 2.53 & 12.34 \\
\hline aNDFom & 287 & 14 & 59.93 & 5.29 & 1.48 & 0.92 & 1.89 & 0.87 & 2.80 & 20.19 \\
\hline uNDF240 & 277 & 14 & 44.04 & 5.76 & 1.65 & 0.92 & 2.24 & 0.86 & 2.57 & 14.30 \\
\hline IVNDFD240 ( $\%$ of aNDFom) & 276 & 12 & 26.09 & 8.69 & 2.68 & 0.90 & 3.43 & 0.85 & 2.53 & 14.00 \\
\hline
\end{tabular}

${ }^{1}$ aNDFom $=$ amylase and sodium sulfite-treated NDF, corrected for ash residue; uNDF240 = undigested NDF estimated via 240-h in vitro fermentation; IVNDFD240 = in vitro aNDFom digestibility after 240-h incubation.

${ }^{2} \mathrm{n}=$ number of samples used in the equation; MPLS terms $=$ number of factors in modified partial least square equation; SEC $=$ standard error of calibration.

${ }^{3} \mathrm{SECV}=$ standard error of cross validation; $1-\mathrm{VR}=$ coefficient of determination of cross-validation, where VR $=$ variance ratio; $\mathrm{RPD}=\mathrm{ratio}$ of performance deviation (SD/SECV); RER = range error ratio (range/SECV). 
(Mentink et al., 2006). Furthermore, the major problems in interpreting NIRS spectra, related to cell wall digestibility, are the high interference of residual water absorbance and the variable absorbance of $\mathrm{C}-\mathrm{H}$ bonds in many spectral regions, which overlaps the absorbance of digestible components of aNDFom and other components (i.e., sugars, starch), as observed by Nousiainen et al. (2004). Despite the fact that the uNDF240 and IVDNDFD240 data are based on complex methods and time-consuming laboratory procedures, they are still reliable and accurate because measuring only the end-point of digestion could avoid problems associated with curve fitting.

Despite several factors that could influence the development of a NIRS calibration for uNDF240, IVNDFD240 and other constituents in fecal samples, the data obtained in the present work showed that uNDF240 should be considered a physical entity composed of several chemical entities that can be well predicted by NIRS. The use of uNDF240 values developed from NIRS calibrations, as an alternative to the traditional technique that requires ADL to estimate iNDF values, could improve the accuracy and use of feed in diet evaluation models for ruminants. Moreover, uNDF240 could be an excellent marker because it can be traced from the diet to the feces. The NIRS technique is well suited for digestibility studies and can be used from in vitro data to develop reliable calibrations and equations.

\section{ACKNOWLEDGMENTS}

This study was supported by the Emilia Romagna regional law n.28/98, as part of the project "Innovazione alimenti zootecnici" coordinated by Centro Ricerche Produzioni Animali (CRPA), Reggio Emilia, Italy.

\section{REFERENCES}

AOAC (Association of Official Analytical Chemists). 1990. Official Methods of Analysis. 15th ed. AOAC, Washington, DC

Barber, G. D., D. I. Givens, M. S. Kridis, N. W. Offer, and I. Murray. 1990. Prediction of the organic matter digestibility of grass silage. Anim. Feed Sci. Technol. 28:115-128.

Barnes, R. J., M. S. Dhanoa, and S. J. Lister. 1989. Standard normal variate transformation and de-trending of near infrared diffuse reflectance spectra. Appl. Spectrosc. 43:772-777. https://doi.org/10 .1366/0003702894202201.

Berzaghi, P., G. Cozzi, and I. Andrighetto. 1997. The use of near infrared analysis for in situ studies. J. Dairy Sci. 80:3263-3270.

Bonfante, E., A. Palmonari, L. Mammi, G. Canestrari, M. Fustini, and A. Formigoni. 2016. Effects of a completely pelleted diet on growth performance in Holstein heifers. J. Dairy Sci. 99:9724-9731.

Cotanch, K. W., R. J. Grant, M. E. Van Amburgh, A. Zontini, M. Fustini, A. Palmonari, and A. Formigoni. 2014. Applications of uNDF in ration modeling and formulation. Pages 114-131 in Proc. Cornell Nutr. Conf., Dept. Anim. Sci., Cornell Univ., Ithaca, NY.
Ferraretto, L. F., A. C. Fonseca, C. J. Sniffen, A. Formigoni, and R. D. Shaver. 2015. Effect of corn silage hybrids differing in starch and neutral detergent fiber digestibility on lactation performance and total-tract nutrient digestibility by dairy cows. J. Dairy Sci. 98:395-405. https://doi.org/10.3168/jds.2014-8232.

Fox, D. G., L. O. Tedeschi, T. P. Tylutki, J. B. Russell, M. E. Van Amburgh, L. E. Chase, A. N. Pell, and T. R. Overton. 2004. The Cornell Net Carbohydrate and Protein System model for evaluating herd nutrition and nutrient excretion. Anim. Feed Sci. Technol. 112:29-78

Fredin, S. M., L. F. Ferraretto, M. S. Akins, P. C. Hoffman, and R. D. Shaver. 2014. Fecal starch as an indicator of total-tract starch digestibility by lactating dairy cows. J. Dairy Sci. 97:1862-1871.

Fustini, M., A. Palmonari, G. Canestrari, E. Bonfante, L. Mammi, M. T. Pacchioli, C. J. Sniffen, R. J. Grant, K. W. Cotanch, and A. Formigoni. 2017. Effect of undigested neutral detergent fiber content of alfalfa hay on lactating dairy cows: Feeding behavior, fiber digestibility, and lactation performance. J. Dairy Sci. 100:44754483. https://doi.org/10.3168/jds.2016-12266.

Goering, H. K. and P. J. Van Soest. 1970. Forage fiber analysis (Apparatus, Reagents, Procedures, and Some Applications). Agricultural Handbook No. 379. USDA Agricultural Research Service, Washington, DC.

Harper, K. J., P. Isherwood, D. G. Barber, M. Callow, D. M. McNeill, and D. P. Poppi. 2014. Prediction of iNDF of subtropical forages by near infrared reflectance spectroscopy. Page 321 in Proc. 30th Biennial Conf. Aust. Soc. Anim. Prod., Canberra, ACT, Australia. http://espace.library.uq.edu.au/view/UQ:354481.

Huhtanen, P., S. Ahvenjärvi, M. R. Weisbjerg, and P. Nørgaard. 2006a Digestion and passage of fiber in ruminants. Pages 87-135 in Ruminant Physiology. K. Sejrsen, T. Hvelplund, and M. O. Nielsen, ed. Wageningen Acad. Publ., Wageningen, the Netherlands.

Huhtanen, P., K. Kaustell, and K. Jaakkola. 1994. The use of internal markers to predict total digestibility and duodenal flow of nutrients in cattle given six different diets. Anim. Feed Sci. Technol. 48:211-227.

Huhtanen, P., J. Nousianinen, and M. Rinne. 2006b. Recent developments in forage evaluation with special reference to practical applications. Agric. Food Sci. 15:293-323.

Krizsan, S. J., L. Nyholm, J. Nousiainen, K. H. Südekum, and P. Huhtanen. 2012. Comparison of in vitro and in situ methods in evaluation of forage digestibility in ruminants. J. Anim. Sci. 90:3162-3173.

Lee, C., and A. N. Hristov. 2013. Short communication: Evaluation of acid-insoluble ash and indigestible neutral detergent fiber as totaltract digestibility markers in dairy cows fed corn silage based diets. J. Dairy Sci. 96:5295-5299.

Lippke, H., W. C. Ellis, and B. F. Jacobs. 1986. Recovery of indigestible fiber from feces of sheep and cattle on forage diets. J. Dairy Sci. 69:403-412.

Lund, P., M. R. Weisbjerg, T. Hvelplund, and K. E. Bach Knudsen. 2007. Determination of digestibility of different forages in dairy cows using indigestible NDF as marker. Acta Agric. Scand. A Anim. Sci. 57:16-29.

Mentink, R. L., P. C. Hoffman, and L. M. Bauman. 2006. Utility of near-infrared reflectance spectroscopy to predict nutrient composition and in vitro digestibility of total mixed rations. J. Dairy Sci. 89:2320-2326.

Mertens, D. R. 1993. Rate and extent of digestion. Chapter 2 in Quantitative Aspects of Ruminant Digestion and Metabolism. J. Forbes and J. France, ed. CAB International, Wallingford, UK.

Mertens, D. R. 2002. Gravimetric determination of amylase-treated neutral detergent fiber in feeds with refluxing in beakers or crucibles: Collaborative study. J. AOAC Int. 85:1217-1240.

Mertens, D. R. 2013. Indigestible versus undigested NDF-The distinction. Unpublished white paper prepared for 2013 Fiber Group meeting, Syracuse, NY.

Norris, K. H., R. F. Barnes, J. E. Moore, and J. S. Shenk. 1976 Predicting forage quality by infrared reflectance spectroscopy. J. Anim. Sci. 43:889-897. 
Nousiainen, J., S. Ahvenjarvi, M. Rinne, M. Hellamaki, and P. Huhtanen. 2004. Prediction of indigestible cell wall fraction of grass silage by near infrared reflectance spectroscopy. Anim. Feed Sci. Technol. 115:295-311.

Palmonari, A., G. Canestrari, M. Fustini, E. Bonfante, L. Mammi, and A. Formigoni. 2017. Technical note: In vitro digestibility of amylase-treated, ash-corrected neutral detergent fiber, with addition of sodium sulfite, at 240 hours with or without rumen fluid reinoculation. J. Dairy Sci. 100:1200-1202.

Palmonari, A., A. Gallo, M. Fustini, G. Canestrari, F. Masoero, C. J. Sniffen, and A. Formigoni. 2016. Estimation of the indigestible fiber in different forage types. J. Anim. Sci. 94:248-254.

Park, R. S., F. J. Gordon, R. E. Agnew, R. J. Barnes, and R. W. J. Steen. 1997. The use of near infrared reflectance spectroscopy on dried samples to predict biological parameters of grass silage. Anim. Feed Sci. Technol. 115:169-178.

Raffrenato, E., and M. E. Van Amburgh. 2010. Development of a mathematical model to predict sizes and rates of digestion of a fast and slow degrading pool and the indigestible NDF fraction. Pages 114-131 in Proc. Cornell Nutrition Conf. Feed Manuf., East Syracuse, NY. Cornell University, Ithaca, NY.

Redshaw, E. S., G. W. Mathison, L. P. Milligan, and R. D. Weisenburger. 1986. Near infrared reflectance spectroscopy for predicting forage composition and voluntary consumption and digestibility in cattle and sheep. Can. J. Anim. Sci. 66:103-115.

Robertson, J. B., and P. J. Van Soest. 1981. The detergent system of analysis and its application to human foods. Pages 123-158 in The Analysis of Dietary Fiber in Foods. W. P. T. James and O. Theander, ed. Marcel Dekker, New York, NY.
Shenk, J. S., and M. O. Westerhaus. 1991a. Population definition sample selection and calibration procedures for near infrared spectra and modified partial least squares regression. Crop Sci. 31:469-474. https://doi.org/10.2135/cropsci1991.0011183X003100020049x.

Shenk, J. S., and M. O. Westerhaus. 1991b. Population structuring of near infrared spectra and modified partial least squares regression. Crop Sci. 31:1548-1555. https://doi.org/10.2135/cropsci1991 $.0011183 X 003100060034 \mathrm{x}$.

Shenk, J. S., and M. O. Westerhaus. 1985. Accuracy of NIRS instruments to analyse forage and grain. Crop Sci. 25:1120-1122.

Shenk, J. S., and M. O. Westerhaus. 1995. Analysis of agricultural and food products by near infrared reflectance spectroscopy. Monograph. Foss-NIRSystems, Silver Spring, MD.

Tilley, J. M. A., and R. A. Terry. 1963. A two-stage technique for the in vitro digestion of forage crops. J. Br. Grassl. Soc. 18:104-111.

Van Amburgh, M. E., R. J. Grant, K. W. Cotanch, A. Zontini, D. A. Ross, and A. Foskolos. 2015. NDF-Making something old, new again. Pages 1-7 in Herd Heath Nutr. Conf., Cornell University, Ithaca, NY; Miner Institute, Chazy, NY.

Williams, P. 2004. Near-infrared technology, getting the best out of light. Pages 12-13 in A Short Course in the Practical Implementation of Near-Infrared Spectroscopy for the User. PDK Grain, Nanaimo, BC, and Winnipeg, MB, Canada.

Williams, P. C., and D. C. Sobering. 1996. How we do it: A brief summary of the methods we use in developing near infrared calibrations. Pages 185-188 in Near Infrared Spectroscopy: The Future Waves. A. M. C. Davies and P. C. Williams, ed. NIR Publications, Chichester, UK. 